resuscitated from state of suspended animation.* The acoidents were, no doubt, chiefiy due to tho circumstance that it had been the custom to use the diluted preparation more freely than pure chloroform would have been used; still they illustrate equally well the comparative safety of diluted and undiluted chloroform, when used on a sponge or handkerchief

Dr. J. Mason Warren has informed me that, since these accidents, the governors of the hospital have prohibited the inhalation of any other agent than sulphuric ether, for preventing pain in surgical operations.

18, Sackrille Street, March 1855.

\section{FATAL INJURIES OF THE HEAD IN CHILDIREN.}

By AUGUSTIx PRICH.ARD, Fsi., Surgeon.to the Bristol Roysl Infirmary.

[Read at the Nceting of the Bath and Bristol Branch, Narcls 29th, 1855.]

THE following twro cases of injury to the head proving fatal in young children, by two very different forms of disease, appear to me to have considerable interest; and, with this view, I venture briefly to bring them before the notice of the Bath and Bristol Branch.

CASE I. Louisa Birt, when two years and a half old, became my patient, in consequence of a blow upon the nose received thrce weeks before, having been previously to this time a healthy child. A week after the receipt of the injury, which does not appear to have been very severe, some thin red fluid cscaped from the nose, and she complained of intolerance of light. When I first saw her, she had ecchymosis of the lids of the right eye, and a hard tumour upon the right side of the temple. I gave the parents some simple application to use, and told them that I thought the case was of a very serious nature. Shortly after this time, the patient became much worse, and the eye was protruded from the orbit by some growth behind the globe. She became then totally blind, and died.

At the post mortem examination, at which, as also at the subsequent one, I had the advantage of Mr. Leonard's assistance, the following extraoräinary condition of disease was discovered. There was soft vascular cancer of both orbits, involving the orbital plates of the frontal bone, the ethnoid, sphenoid, and the contiguous dura mater. There were several tumours within the cranium, between the bone and the dura mater, upon the temple, the vertex, the occiput, and base, but exactly opposite each separate internal tumour (all of which were somewhat flattened), was a rounded or oval cancerous swelling in a corresponding part of the scalp. The intermediate bone, as far as appearances went, was healthy. The rest of the body was not examined.

CABE Ir. A boy, Edward Bailey, aged 9 ycars, received a blow upon the left side of his face and nose, three weeks before he was admitted as my patient. The blow made his nose bleed at the time, and, after a week, he had headache, giddiness, and sickness. When the second week from the receipt of the injury had elapsed, the eye began to suffer. Upon his admission, three weeks after the blow, he had prominent eye (exophthalmos in ophthalmic language), amaurosis, ccmplete ptosis or drooping of the lids, and immovable eye, with very dilated pupil and entire destruction of sight. I suspected suppuration in the orbit; but there was no evidence of any abscess pointing, nor was there any special indication for surgical or medical treatment. I gare him a small dose of grey powder, a simple lotion for the eyes, and applied a blister to his temple. This was on the 27th of last December. On the 31 st, he was evidently worse, and appeared to be suffering from sleeplessness, with headache and giddiness. I ordered him

- New York Journal of Medicine, vol. x. New series, 1833. four drops of laudanum at bed-time. He now became unable to attend as an out-patient; and his father brought an occasional report of his symptoms until the 11th of January, when the boy died, after being convulsed and insensible for a day or two.

Upon proceeding to examine the head, I was much struck with the complete absence of anything like prominence of the eyeball, which had been 50 marked a symptom during life. The friends informed us that the eye suddenly returned to its place some time after death. There was a small quantity of pus on the floor of the left orbit, with a little carious opening through the orbital plate of the superior maxillary bone leading into the antrum. There was pus in the cavernous sinus of each side, extending into every opening from both, namely, the sphenoidal sinus, forainen rotundum and ovale, and running a short distance with the nerves of both sides. The sella turcica of the sphenon was also filled with purulent matter. The right side of the brain, and more particularly its anterior portion, was extremely rascular externally; and within was found a vast extravasation of dark and partially coagulated blood, filling the whole hemisphere, which appeared to be quite broken down through its entire structure.

RENARKS. I am quite in the dark as to the reason why purulent infiltration of the surrounding tissues, followed by apoplexy, should have been the result of injury in one case, or why in the other cancerous disease of extraordinary malignancy should be dereloped from an exactly similar cause. The only practical hint that I can deduce from these two facts is, besides a confession of the helplessness of all our present treatment in cases so rapidly fatal, a caution regarding our predictions in any instance where the effects of an injury in young subjects are not of a temporary and transitory nature.

Clifton, March 1ะ55.

\section{CASE OF IITHOTOMY : OPERATION IN THE MEDIAN LINE.}

By JOSEPH HINTON, Esq.

[Read at the Mecting of the Bath and Bristol Branch, IIarch 29, 1855.]

A FBW wecks since, the Association Jodresu contained the review of a little work by Mr. Allarton, entitled Lithotomy Simplified. On perusing the work itself, I was struck with the apparent simplicity of the operation, and determined, if opportunity offered, to adopt it. At that very time, one of the miners on the Blaina works, aged about 40 , was suffering from symptoms of stone; and, on a careful examination, the calculus was detected. He had been suffering for more than twelve months, but did not like to apply for relief, until at last his distress and suffering forced him. He was apparently healthy; and, after some persuasion, I prevailed on him to allow me to remove the calculus.

Accordingly, about three weeks since, assisted by my friend Mr. Scott, of Newport, and my own assistant, I proceeded to operate after the plan laid down by Mr. Allarton. Although, ou sounding him in the morning, I had plainly felt the stone, and he himself distinctly heard the sound strike it, we could not detect it when he was placed on the table previous to operating. The injection of a little water removed the difficulty. The perineum was exceedingly, dcep; and, on piercing it in the median line, I feared that I must have missed the groove, and accordingly I withdrew the knife, and explored the wound with my finger. I found that the staff had not been reached; this was immediately done, and the incision completed. The urethra being opened, no water escaped. On the first introduction of my finger as a dilator, I immediately felt the stone; but it appeared so small that I could not believe it to be the only cause of his distress. Accordingly, I did not wait to remove it, but proceeded with my efforts at dilatation; in a very short time I found the calculus in the wound, and with one finger in the wound, and the other index finger in the rec- 
tum, tilting up the calculus, it was remored without any emplorment of the forceps. The stone was round, and of about the size of a small horse-bean. The amount of blood lost during the operation was trifling. No other stone could be detected. A sponge was now applied to the wound, and retained in position by a bandage.

To detail the daily progress of the case would be tedious, and without any practical importance. When the patient first passed urine after the operation, a few drops escaped by the urethra; but in less than forty-eight hours this was reversed, and he retained the urine for four or five hourslonger, in fact, than he had done for months. On the third day, I allowed him to get up and have his clothes on. The wound appeared almost healed; in fact, he considered himself well. On the subsequent day to the operation he appeared slightly feverish, but this passed off almost immediately. In a few days, he brought over to my surgery the bandages; and he appeared perfectly well.

RexskKs. Had I been in the position of meeting with frequent examples of this disease, I should have hesitated before laying an isolated case before the members of this Branch; but when I reflected that years might pass, and no cases present themselres, I considered it the wiser plan to add my mite of experience at once.

I must confess that my own feelings were not at first so farourable to the operation. I attribute this not to the operation itself, but to my own preconceived notions. I expected to find a larger, though not a large stone; and hence I continued efforts at dilatation, which were unnecessary, and which rendered the operation much longer. These feelings were very speedily dissipated by finding the recovery so rapid. Instend of the usual anxieties attendant on the lateral operation, I was able at once to set my mind at rest; and, even if the rapid recovery were the only advantage attending this modification, it is a point of the utmost importance, where a family is dependent on the exertions of the sufferer.

When I reflect on the dangers of the lateral operation, éven when skilfully performed by the experienced handdangers many of which, though within the ken, are beyond the control of the operator-I cannot but think that this simple modification of the Marian operation, as recommended by Mr. Allarton, is a boon to the profession, and one that will increase in favour in proportion to the extent of its trials.

Blaina Iron Works, Mrarch 1835.

\section{PREVENTION OF ENTRANCE OF AIR IN PARACENTESIS THORACIS.}

\section{BY T. WALKER, M.D.}

DR. WAtsor states, as one of the most important objections to the operation of paracentesis thoracis, the probable entrance of air into the pleural sac; and, as I regard this operation as one by which great and immediate relief may be afforded, under circumstances of extreme distress, and when death from suffocation is imminently impending, I consider it important to shew that the admission of air is perfectly and easily aroidable hy a very simple arrangement.

Ihet a piece of quill, fitted to the tube of the canula, be prepared by wrapping round it, and securing with a bit of thread, a small piece of thin wash leather or sheepskin, rendered limp by wetting it. Immediately on withdrawing the trocar, this quill is introduced into the canula: the wet leather forms a pendulous prolongation of the tube, an inch and a half long, or a little more, through which the fluid will flow freely; but the moment that the slightest act of suction takes place, which, as the chest gets empty, invariably happens, it will act as a valve, and prerent the possibility of any air entering by the tube of the canula.

I need not here state the precautions necessary in order to prevent, whether during the operation or after it, the entrance of air by the opening made by the trocar, as they are generally known, and would, as a matter of course, be adopted.

I have never performed the operation of paracentesis thoracis, unless when it was evidently and urgently required. I have nerer seen it fail to gire great and immediate relief. In all heres effusion, the patient has recovered; and in the only case in which the patient died-one of empyema with tubercular phthisis-although ho ultimately sank from the pulmonary disease, the urgent distress from dyspnoa, threatening immediate dissolution, was entirely relieved, and his life was prolonged for several months after the operation.

I saw to-day a young man, now in good bealth, from whose left pleural cavity I drew off, on the 28th of January, ten pints of serum, the effusion consequent to an attack of subacute pleuritis, of at least four months' standing. I only refer to this case, however, in order to say that using the simple apparatus which $I$ have described, not a particle of air entercd the pleural sac; nor has this disagreeable incident ever occurred, either in ny own hands, when I have used this plan, or in those of any of my friends, who have at my suggestion adopted the same modification of means as simple as they are effectual.

Peterborough, Brarch 2C, 18:55.

\section{REPORTS OF SOCIETIES.}

\section{ROYAL MEDICAL AND CHIRURGICAL SOCIETY.}

TUESDAY, Marci 13TH, 1855 .

Cesar Hawkins, Esq., l'resident, in the Chair.

On taking the chuir, Mr. Hawkiss thanked the Fellows for the bonour they had done him in electing him their President. Alluding to the disagreements which had taken place during the past year, he trusted that they would not be renewed, and that the acute disease under which the Society had laboured would not become a chronic one.

NOTES ON IITHOTRITY, WITI AN ACCOCNT OF THE RESLLTS OF the OPERATION IY THE AUTHOR'S PRACTICE. BY SIR B. C. BRODIE, B.RT.

The anthor announced that his chief objects were-to communicate, in a series of notes, some observations as to those circumstances which are especially deserving of attention, with a view to the success of the operation; to give a brief but accurate account of the actual results of his own practice; and to add some observations as to the amount of danger involved in the operation by crushing, conpared with that which belonga to lithotomy. He adduced reasons why this operation was not applicable to the period of youth, nor generally common or necessary in females. He preferred the forceps worked by a screw to that in which the force is applied by means of a rack, since the latter, though affording sorne advantages in the way of greater expedition, must be manifestly deficient in power as compared with the screw. The nuthor remarked that no prudent surgeon would willingly undertake this operation unless the bladder admitted of the injection and retention of from four to six ounces of tepid water; and that where this power had been lost, it had in all his cases but one been restored by keeping the patient in the recumbent position for seven or fourteen days, and injecting the bladder daily. He then described the steps of the operation, urging the great necessity for the gentlest possible manipulation of the forceps, that injury may be aroided, pain diminished, and, by consequence, the bladder rendered less prone to contract upon its contents; that, with these points in view, the forceps should never be used as a sound for the purpose of exploring the bladder or ascertaining the position of the calculus, but that the convex part of its curved extremity should be brought into contact rith, and gently pressed against, the posterior and lorrer surface of the bladuer by the elevation of its handle; that if, when in this position, on the blades being separated, the stone does not fall into it ly its own weight, the instrument may be slightly struck on one of its sides, which slight concussion will probably dislodge the calculus from its fixed position and cause it to fall; if unsuccessful in this, the forceps may be very cantiously turned to one side or the other, and the same rules followed in that position as before; but a freer use of the instrument should never be made, not eren in 